\title{
Changes in serum RANKL and OPG with sexual development and their associations with bone turnover and bone mineral density in a cohort of girls
}

\author{
Raquel Lucas a,b,*, Elisabete Ramos a,b, Margarida Prata ${ }^{\mathrm{b}}$, Ana Maria Rodrigues ${ }^{\mathrm{c}, \mathrm{d}}$, Lúcia Costa e \\ Milton Severo ${ }^{\mathrm{a}, \mathrm{b}}$, Helena Canhão ${ }^{\mathrm{c}, \mathrm{d}}$, João Eurico Fonseca ${ }^{\mathrm{c}, \mathrm{d}}$, Henrique Barros ${ }^{\mathrm{a}, \mathrm{b}}$ \\ a Institute of Public Health of the University of Porto, Porto, Portugal \\ ${ }^{\mathrm{b}}$ Department of Hygiene and Epidemiology, University of Porto Medical School, Porto, Portugal \\ c Rheumatology Research Unit, Instituto de Medicina Molecular, Faculdade de Medicina da Universidade de Lisboa, Lisbon, Portugal \\ ' Serviço de Reumatologia e Doenças Ósseas Metabólicas, Hospital de Santa Maria, Lisbon, Portugal \\ e Serviço de Reumatologia, Hospital de São João, Porto, Portugal
}

\section{A R T I C L E I N F O}

\section{Article history:}

Received 7 January 2014

Received in revised form 21 March 2014

Accepted 11 April 2014

Available online 22 April 2014

\section{Keywords:}

Osteoprotegerin

RANK ligand

Bone turnover

Bone mineral density

Longitudinal study

Adolescence

\section{A B S T R A C T}

Objectives: To characterize the variations of serum osteoprotegerin (OPG) and RANK ligand (RANKL) with sexual development in adolescent girls, and to estimate their associations with bone turnover and bone mineral density (BMD).

Design and methods: We studied 300 girls evaluated at 13 and 17 years of age. Fasting blood samples were collected and the following substances were quantified: RANKL, OPG, C-terminal telopeptide of type I collagen (CTX), and procollagen type I N propeptide (PINP). BMD was measured at the distal forearm. Correlation coefficients were used to quantify associations between those variables at 13 and 17 years of age. Random-effects linear models were used to quantify associations between bone parameters and sexual development (years from menarche).

Results: RANKL was positively correlated with bone resorption (CTX) in early and late adolescence $\left(\mathrm{r}_{13}=0.15\right.$ and $\left.r_{17}=0.23\right)$ and the OPG/RANKL ratio correlated inversely with CTX at $17\left(r_{17}=-0.24\right)$. No significant associations were found between RANKL and OPG and bone formation (PINP). In early adolescence, there was an inverse correlation of BMD with CTX $\left(\mathrm{r}_{13}=-0.52\right)$ but no significant correlations were found between osteoclast regulators and BMD. We observed a linear decrease in serum RANKL with increasing sexual development $(-0.09 \mathrm{pmol} / \mathrm{L}$ per year, $95 \% \mathrm{Cl}:-0.10,-0.07)$ alongside an increase in OPG $(0.02 \mathrm{pmol} / \mathrm{L}, 95 \% \mathrm{Cl}: 0.01,0.04)$.

Conclusions: Serum RANKL and OPG levels varied markedly with sexual development in adolescence. These cytokines were not predictive of bone turnover or BMD at 13, but serum RANKL bioactivity was associated with bone resorption in late adolescence.

(C) 2014 The Canadian Society of Clinical Chemists. Published by Elsevier Inc. All rights reserved.

\section{Introduction}

Fracture risk combines genetic background with a complex set of exposures that act throughout the life course, influencing the resistance of bone to trauma [1]. Bone strength is the complex end result of size, morphology, material properties and peak bone mass attained during the first three decades of life [2], in addition to subsequent mineral loss. Understanding how bone dynamics evolves early in life is a key component of research on the etiology of adult bone fragility. The

Abbreviations: OPG, osteoprotegerin; RANKL, receptor activator of nuclear factor kB ligand; PINP, procollagen type I N propeptide; CTX, and serum C-terminal telopeptide of type I collagen; BMD, bone mineral density; DXA, dual-energy X-ray absorptiometry.

* Corresponding author at: Department of Clinical Epidemiology, Predictive Medicine and Public Health, University of Porto Medical School, Alameda Prof. Hernâni Monteiro, 4200319 Porto, Portugal. Fax: +351225513653.

E-mail address: rlucas@med.up.pt (R. Lucas). potential for prevention is particularly interesting in the female gender, where the burden of fragility fractures is disproportionately high [3].

The final physical properties of bone tissue are dependent on its continuous turnover [4]. In adults, the main homeostatic mechanism driving bone dynamics at the local level is remodeling, which involves coupling of bone formation and resorption in such a way that overall mineral mass remains fairly constant [4]. During childhood, in addition to remodeling, growth demands for substantial changes in bone size and shape that are achieved through modeling, in which matrix synthesis and degradation take place in different locations within the bone tissue and are thus uncoupled [5]. Since modeling is a vigorous process that results in rapid longitudinal changes in bone structure and material, bone is an even more dynamic organ during childhood and adolescence.

Bone status can be characterized by physical properties that reflect the cumulative process of bone accrual up to the time of measurement, and also by turnover parameters, which are dynamic measures of short-term 
systemic or local effects [6,7]. A major regulator of turnover at the bone tissue level is the osteoprotegerin (OPG)/receptor activator of nuclear factor $\mathrm{kB}$ (RANK)/RANK-ligand (RANKL) system, which mediates the local effects of systemic modulators, such as hormones and cytokines $[8,9]$. Throughout the life course, this system is essential for bone turnover since the relative expression of RANKL and its decoy receptor OPG regulates osteoclast differentiation, activation and survival $[8,10]$. There is evidence that these mediators may have a particularly relevant role in early life, as they are expressed by hypertrophic chondrocytes in epiphyseal plates, probably regulating linear bone growth [11]. Despite their essential role in bone metabolism [12,13], little is known about how circulating levels of these cytokines evolve before peak bone mass or on whether they directly relate to bone strength and turnover markers $[14,15]$. On the other hand, collagen turnover markers are indicators of bone formation or resorption rates, although high inter- and intraindividual variability have led to limited application in clinical practice [16]. The International Osteoporosis Foundation and the International Federation of Clinical Chemistry and Laboratory Medicine recently recommended the use of serum procollagen type I N propeptide (PINP) and serum C-terminal telopeptide of type I collagen (CTX), respectively, to monitor treatment response in clinical trials of osteoporosis therapies [17]. It is unclear whether this set of markers and their relative concentration may also be responsive to intraindividual changes in bone metabolism during normal growth.

During early adolescence, a stage of rapid bone accrual, sexual maturation regulates the cessation of linear growth and the improvement in bone mechanical resistance after peak height velocity [18]. Therefore, changes in bone properties during adolescence should be regarded as a function of sexual development, in addition to chronologic age. Previous studies describing bone status and turnover parameters in adolescence have been mostly conducted cross-sectionally in samples with wide age ranges, impairing the detection of heterogeneity across ages or sexual development stages [19-22]. Other studies were conducted among children with disorders that potentially disturb normal bone metabolism and therefore have limited generalizability [23-25].

In the present study, our objective was to assess if serum levels of OPG and RANKL predict bone turnover and forearm bone mineral density in early and late adolescence, and to describe changes in those cytokines in relation to chronologic age and sexual development, measured as time from menarche.

\section{Materials and methods}

We used data from a sample of 300 adolescent girls, recruited and followed up as part of the EPITeen prospective investigation, comprising a cohort of adolescents born in 1990 and attending public and private schools in Porto, Portugal.

\section{EPITeen cohort assembly and follow-up}

Recruitment of the cohort took place during the 2003/2004 school year. All 51 schools in the city attended by children born in 1990 were contacted and 46 agreed to provide contact details for students and their families. Study objectives and procedures were explained in detail in meetings with teachers and parents, as well as through written materials. Students and their legal guardians were contacted and asked to participate. Among the 2787 eligible adolescents identified, $78 \%$ (2160 girls and boys) agreed to participate by providing information for at least part of the planned protocol, which included questionnaires, physical examination, and blood sample collection. After this early adolescence evaluation, participants were contacted again during the $2007 / 2008$ school year for a reevaluation using the same protocol. Of the initial cohort, $80 \%$ completed the late adolescence assessment. In both evaluations, written informed consent was obtained from adolescents and legal guardians. The study protocol complied with the Declaration of Helsinki and was approved by the Ethics Committee of the University Hospital of São João in Porto, Portugal. Methods have been described in detail elsewhere [26].

The study of bone development using bone mineral density as the main outcome has been a research area since the inception of the cohort. Before cohort recruitment in 2003, still little was known about the clinical significance of serum OPG and RANKL levels as regulators of bone biology in human populations and thus the analytical measurements presented in this paper were not part of the initial plan. More recently the system's role became increasingly clear as did the limitations in published populational evidence on the topic, especially in adolescence. Since we had the consent of adolescents and guardians to investigate bone development namely through the blood samples collected in both evaluations, we were able to adapt of one of the branches of our research plan to evolving knowledge on bone biology.

\section{Study sample}

The initial cohort included 1116 girls. Of those, 892 were evaluated at 13 and 17 years of age and 726 had complete information on bone mineral density and anthropometry in both evaluations. Missing information was largely due to losses to follow-up or unavailability of the bone densitometry equipment at the time of evaluation. Girls that were not eligible for the present study were not significantly different from the remaining cohort regarding baseline height (158.2 vs. $158.1 \mathrm{~cm}, \mathrm{p}=0.763$ ) but were heavier than eligible participants at 13 years of age ( $54.5 \mathrm{vs.} 52.3 \mathrm{~kg}, \mathrm{p}=0.001)$ and had higher forearm $\operatorname{BMD}\left(0.367\right.$ vs. $0.358 \mathrm{~g} / \mathrm{cm}^{2}, \mathrm{p}=0.033$ ).

For this study we conducted stratified sampling: from the 726 girls with complete information, we selected a random sample of 150 within each of two categories of body mass index (normal weight and overweight). This option was chosen to optimize statistical power throughout the whole spectrum of BMI. When testing overweight as a modifier of the associations estimated we found no differences across BMI strata and we opted to retain the actual sample size rather than presenting weighted estimates for the different sampling fractions.

As a general strategy, we chose a sample size that would allow us to detect even weak correlations $(<0.2)$ with a statistical power near 0.80 $\left(\mathrm{H}_{0}\right.$ : rho $\left.=0\right)$. Since several different correlation magnitudes could be expected from the literature, no single sample size could be expected to yield a constant statistical power. For our effective sample size of 300 , we indexed the description to the value of correlation that would provide a 0.80 statistical power, i.e. rho $=0.16$ (significance set at 0.05 , using the command power onecorrelation in Stata 13.0). Since the null hypothesis in significance testing was of no association, which is a low cutoff in terms of biological meaning, when interpreting the results we valued correlations above 0.2 . This means that our sample size allowed an $80 \%$ power for all the correlations that we believed were clinically relevant.

Even though our cohort included both genders we restricted this study to girls. Because of lack of optimal privacy at the schools where adolescents were evaluated, we were not able to assess pubertal development through Tanner staging. Whereas in girls we were able to overcome this limitation through the use of menarche age, we did not have a surrogate for sexual development in boys of this cohort, which limited our ability to answer the present objectives in males.

\section{Physical examination}

In both evaluations, bone mass was estimated through areal bone mineral density (BMD), measured in $\mathrm{g} / \mathrm{cm}^{2}$ at the distal radius of the non-dominant forearm by dual-energy X-ray absorptiometry (DXA) using a Lunar® Peripheral Instantaneous X-ray Imager (PIXI) device. In the case of reported previous fracture of the non-dominant arm, the dominant arm was the one assessed. Anthropometry was obtained while the student stood barefoot in light indoor clothing. Weight was measured to the nearest tenth of kilogram (Tanita ${ }^{\circledR}$ scales), and height 
was measured in centimeters, to the nearest tenth, using a portable stadiometer (Seca®).

\section{Clinical and behavioral information}

Clinical and behavioral characteristics were collected in both evaluations using self-administered questionnaires. One of the questionnaires was completed at home with parental assistance and included clinical history (chronic diseases and medication use in the previous month) and use of vitamin or mineral supplements, including calcium and vitamin D preparations, and a food frequency questionnaire, from which average daily nutrient intake was converted with the software Food Processor. Oral contraceptive use at the time of inquiry was collected through a questionnaire filled in at school. Menarche age was also inquired at school and time relative to menarche age in each evaluation was estimated, as the absolute difference in years between menarche age reported in late adolescence and the age at each assessment (e.g. for a girl whose menarche age was 12 years and was evaluated at 13 and 17 years of age, time relative to menarche would be -1 in the first and 5 in the second assessment).

\section{Serum determinations}

For each girl, two 12-hour overnight fasting blood samples were collected, at 13 and 17 years of age (2003/2004 and 2007/2008, respectively). Samples were drawn from an antecubital vein between 8:00 and 10:00 am, centrifuged for $15 \mathrm{~min}$ at $1500 \times \mathrm{g}$ and aliquoted. Immediately after samples were stored frozen at $-80^{\circ} \mathrm{C}$ in the population-based biobank at the University of Porto Medical School until the day of analysis. All analytical measurements presented in this paper were conducted in 2011-2012. In order to reduce extraneous variability, samples were paired so that both sera of each participant were examined in the same plate. We quantified the soluble form of receptor activator of nuclear factor kB ligand (RANKL) with a highly sensitive assay (PromoKine, PromoCell GmbH, Germany). This kit included an additional enhancement system for the amplification of the detection signal, lowering the detection limit to $0.02 \mathrm{pmol} / \mathrm{L}$. RANKL levels below the limit of detection were found in four samples at 13 and in 73 samples at 17 years of age. In order to avoid left-censoring of the distribution due to exclusion of these observations, we used as imputation value for these individuals a concentration equal to the detection level divided by the square-root of two $(0.01 \mathrm{pmol} / \mathrm{L})$. For quantifying osteoprotegerin (OPG) we used a kit that quantified serum concentration of all forms of this cytokine: monomer, dimer and bound to RANKL (RayBiotech, Inc., USA), with a detection limit of $1 \mathrm{pg} / \mathrm{mL}$ ( $0.014 \mathrm{pmol} / \mathrm{L})$. As a measure of RANKL bioactivity, serum OPG/RANKL molar ratio was calculated after converting the serum OPG metric concentrations (molecular weight $71 \mathrm{kDa}$ ) to pmol/L. C-terminal telopeptide of type I collagen (CTX), an eight-amino acid fragment from the C-terminal telopeptide region of the $\alpha 1$ chain of type I collagen was determined using a Serum Cross Laps assay (Immunodiagnostic Systems Ltd.). The detection limit was less than $0.020 \mathrm{ng} / \mathrm{mL}$. Procollagen type I N propeptide (PINP) is the N-terminal extension removed from procollagen during collagen type I synthesis. This marker of bone formation was quantified using a Cusabio Biotech Co. kit with a detection limit under $4.7 \mathrm{pg} / \mathrm{mL}$. As a relative measure of resorption to formation, we calculated the ratio between CTX and PINP concentrations expressed as percentage.

\section{Data analysis}

Height, weight, forearm BMD and serum levels of bone parameters were described as means and $95 \%$ confidence intervals $(95 \% \mathrm{CI})$ at 13 and 17 years of age and as average variation per follow-up year. To assess whether the ranks of individuals in the distributions of bone parameters were maintained during follow-up, we calculated Spearman's correlation coefficients between these variables at 13 and 17 . These coefficients were also used to quantify the crude associations between height, weight, and BMD and all of the serum parameters at each age, as well as between variations in these parameters from 13 to 17 years of age. Individual trajectories of each bone parameter were graphically represented according to time from menarche in years, and overall trajectories were depicted using lowess regressions. In order to account for intraindividual dependency, we quantified the associations between bone parameters and time relative to menarche using a random-effects linear regression model with random intercepts fitted via maximum restricted likelihood, using the xtmixed command in Stata 12.0.

\section{Results}

\section{Sample characteristics}

In this sample of 300 girls, $13.8 \%$ were premenarcheal at 13 years of age and all were postmenarcheal by 17 . The presence of conditions associated with altered bone metabolism was reported by three adolescents ( $1 \%$ of the sample) and included hyperthyroidism, anorexia nervosa, and renal disease. The use of medication with a potential deleterious effect on bone mass (inhaled corticosteroids, anticonvulsants, and thyroid hormone replacement therapy were reported) was also infrequent: $2.7 \%$ of girls at 13 and $3.3 \%$ at 17 years of age. Median (25th-75th percentiles) calcium intake was 1103 (791-1409) mg/day and median vitamin D intake was $4.0(2.9-5.6) \mu \mathrm{g} /$ day. Calcium or vitamin D supplement use was uncommon in both evaluations (1\% at 13 and $0.7 \%$ at 17 years of age). At 17 years of age, 76 (25.4\%) girls reported using oral contraceptives.

\section{Changes in bone parameters during adolescence}

Between 13 and 17 years of age, forearm bone mineral density increased on average $0.023 \mathrm{~g} / \mathrm{cm}^{2} *$ year $(95 \% \mathrm{CI}$ : $0.022,0.025)$, height $0.92 \mathrm{~cm} /$ year $(95 \%$ CI: $0.83,1.01)$ and weight $1.40 \mathrm{~kg} /$ year (95\% CI: 1.21 , 1.59). RANKL changed $-0.12(95 \% \mathrm{Cl}:-0.13,-0.10) \mathrm{pmol} / \mathrm{L} *$ year while OPG varied on average $0.03 \mathrm{pmol} / \mathrm{mL} *$ year $(95 \% \mathrm{CI}: 0.01,0.04)$. Mean variation in serum CTX was -0.10 (95\% CI: $-0.12,-0.08)$ $\mathrm{ng} / \mathrm{mL} *$ year and PINP changed $-0.34 \mathrm{ng} / \mathrm{mL} *$ year $(95 \% \mathrm{CI}:-$ $0.38,-0.30$ ) between 13 and 17 years of age (Table 1$)$.

Correlations between osteoclast regulators, markers of turnover and bone mineral density

Pairwise correlation coefficients between variables presented in Table 2 were calculated cross-sectionally, at each age $\left(r_{13}\right.$ and $\left.r_{17}\right)$ and also regarding the change observed between evaluations ( $\left.r_{\text {change }}\right)$. Regarding associations between markers of bone turnover, at 13 years of age, the correlation between serum RANKL and CTX was positive and significant and it increased by 17 years of age $\left(r_{13}=0.15\right.$ and $r_{17}=$ $0.23)$. OPG was only weakly correlated with PINP in late adolescence $\left(\mathrm{r}_{17}=-0.13\right)$. The OPG/RANKL ratio was inversely correlated with serum CTX at 17 years of age $\left(r_{17}=-0.24\right)$ (Table 2$)$.

Analyzing the association between those parameters and BMD, at 13 years of age we observed an inverse and significant correlation of CTX with BMD $\left(r_{13}=-0.52\right)$, which was vastly attenuated by 17 years of age $\left(r_{17}=-0.12\right)$. No significant correlations were found between osteoclast regulators (RANKL, OPG or the OPG/RANKL ratio) and BMD at 13 or 17 years of age (Table 2). There were no significant longitudinal associations between osteoclast regulators or markers of bone turnover measured at 13 and BMD at 17 years of age.

\section{Time relative to menarche and changes in bone parameters}

With the objective of exploring the possible effect of sexual development, in addition to chronologic age, on serum levels of osteoclast regulators and turnover markers, Fig. 1 presents adolescents' individual and 
Table 1

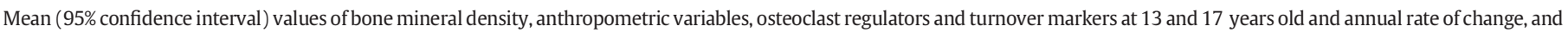
correlations between values in early and late adolescence.

\begin{tabular}{|c|c|c|c|c|}
\hline & 13 years old & 17 years old & Annual variation & Spearman's correlation (13 v. 17) \\
\hline Forearm bone mineral density $\left(\mathrm{g} / \mathrm{cm}^{2}\right)$ & $\begin{array}{l}0.366 \\
(0.359,0.372)\end{array}$ & $\begin{array}{l}0.441 \\
(0.435,0.446)\end{array}$ & $\begin{array}{l}0.023 \\
(0.022,0.025)\end{array}$ & $\begin{array}{l}0.67 \\
(p<0.001)\end{array}$ \\
\hline Height (cm) & $\begin{array}{l}158.5 \\
(157.8,159.2)\end{array}$ & $\begin{array}{l}161.4 \\
(160.8,162.1)\end{array}$ & $\begin{array}{l}0.92 \\
(0.83,1.01)\end{array}$ & $\begin{array}{l}0.91 \\
(\mathrm{p}<0.001)\end{array}$ \\
\hline Weight (kg) & $\begin{array}{l}54.9 \\
(53.7,56.2)\end{array}$ & $\begin{array}{l}59.4 \\
(58.2,60.6)\end{array}$ & $\begin{array}{l}1.40 \\
(1.21,1.59)\end{array}$ & $\begin{array}{l}0.82 \\
(p<0.001)\end{array}$ \\
\hline RANKL (pmol/L) & $\begin{array}{l}0.58 \\
(0.52,0.63)\end{array}$ & $\begin{array}{l}0.20 \\
(0.17,0.24)\end{array}$ & $\begin{array}{l}-0.12 \\
(-0.13,-0.10)\end{array}$ & $\begin{array}{l}0.54 \\
(p<0.001)\end{array}$ \\
\hline $\mathrm{OPG}(\mathrm{pmol} / \mathrm{L})$ & $\begin{array}{l}0.56 \\
(0.49,0.63)\end{array}$ & $\begin{array}{l}0.65 \\
(0.59,0.70)\end{array}$ & $\begin{array}{l}0.03 \\
(0.01,0.04)\end{array}$ & $\begin{array}{l}0.41 \\
(\mathrm{p}<0.001)\end{array}$ \\
\hline OPG/RANKL & $\begin{array}{l}3.58 \\
(1.77,5.40)\end{array}$ & $\begin{array}{l}26.5 \\
(18.48,34.49)\end{array}$ & $\begin{array}{l}7.30 \\
(4.61,10.00)\end{array}$ & $\begin{array}{l}0.47 \\
(p<0.001)\end{array}$ \\
\hline CTX (ng/mL) & $\begin{array}{l}1.48 \\
(1.41,1.55)\end{array}$ & $\begin{array}{l}1.15 \\
(1.09,1.20)\end{array}$ & $\begin{array}{l}-0.10 \\
(-0.12,-0.08)\end{array}$ & $\begin{array}{l}0.48 \\
(p<0.001)\end{array}$ \\
\hline PINP (ng/mL) & $\begin{array}{l}69.2 \\
(68.0,69.3)\end{array}$ & $\begin{array}{l}68.1 \\
(68.0,68.2)\end{array}$ & $\begin{array}{l}-0.34 \\
(-0.38,-0.30)\end{array}$ & $\begin{array}{l}0.30 \\
(\mathrm{p}<0.001)\end{array}$ \\
\hline CTX/PINP (\%) & $\begin{array}{l}2.1 \\
(2.0,2.2)\end{array}$ & $\begin{array}{l}1.7 \\
(1.6,1.8)\end{array}$ & $\begin{array}{l}-0.14 \\
(-0.17,-0.11)\end{array}$ & $\begin{array}{l}0.49 \\
(p<0.001)\end{array}$ \\
\hline
\end{tabular}

average trajectories of bone and anthropometric parameters from 13 to 17 years of age, according to time relative to menarche (i.e. the difference between the age at each evaluation and menarche age).

Table 3 provides the corresponding linear regression coefficients for the effects of time relative to menarche, taking into account the random effect of the individual. Bone mineral density, height and weight increased more steeply up to the time of menarche but the rates decreased thereafter, as seen by the significant quadratic term for time relative to menarche, which shows that menarche timing added important information on the rate of change in addition to chronologic age. Consistently, serum CTX and the CTX/PINP ratio decreased at a higher rate in earlier stages of gynecologic development and at a lower rate in post-menarcheal years. In contrast, serum RANKL, OPG and PINP changed at an approximately constant rate throughout time relative to menarche (i.e. menarche timing did not add relevant information on the rate of change, in addition to the average trajectory predicted by chronologic age): we observed a linear decrease in serum RANKL with increasing time relative to menarche $(-0.09 \mathrm{pmol} / \mathrm{L}$ per year, $95 \% \mathrm{CI}:-0.10,-0.07)$ that remained significant after logtransformation, while OPG increased linearly in this period $(0.02 \mathrm{pmol} / \mathrm{L}$ per year, $95 \% \mathrm{CI}: 0.01,0.04$ ) and PINP changed $-0.22 \mathrm{ng} / \mathrm{mL}$ per year (95\% CI: $-0.26,-0.18$ ). RANKL bioactivity, measured as serum OPG/ RANKL, increased at a higher rate with increasing sexual development, as seen through the lowess curve, but its variance also increased substantially in that period, which impaired fitting of a quadratic model. Log-transformed OPG/RANKL was linearly associated with time relative to menarche (Table 3).

After taking into account menarche age, no further differences were found between girls who reported using oral contraceptives and those who did not. Additionally, the exclusion of the 13 girls with clinical conditions that could affect bone metabolism had no significant impact on the results.

Table 2

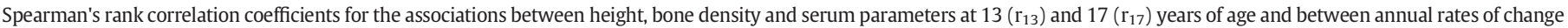
( $\left.\mathrm{r}_{\text {change }}\right)$.

\begin{tabular}{|c|c|c|c|c|c|c|c|c|}
\hline & Height (cm) & Weight (kg) & $\operatorname{BMD}\left(\mathrm{g} / \mathrm{cm}^{2}\right)$ & RANKL (pmol/L) & $\mathrm{OPG}(\mathrm{pmol} / \mathrm{L})$ & OPG/RANKL & CTX (ng/mL) & PINP (ng/mL) \\
\hline \multirow[t]{3}{*}{ Height (cm) } & 1 & $r_{13}=0.45^{c}$ & $r_{13}=0.18^{b}$ & $\mathrm{r}_{13}=0.01$ & $r_{13}=-0.02$ & $r_{13}=-0.04$ & $\mathrm{r}_{13}=-0.14^{\mathrm{a}}$ & $r_{13}=0.06$ \\
\hline & & $r_{17}=0.38^{c}$ & $r_{17}=-0.06$ & $\mathrm{r}_{17}=0.09$ & $r_{17}=0.02$ & $r_{17}=-0.11$ & $r_{17}=0.03$ & $r_{17}=0.00$ \\
\hline & & $r_{\text {change }}=0.40^{c}$ & $r_{\text {change }}=0.44^{c}$ & $\mathrm{r}_{\text {change }}=-0.01$ & $\mathrm{r}_{\text {change }}=-0.07$ & $r_{\text {change }}=-0.18^{b}$ & $\mathrm{r}_{\text {change }}=-0.38^{\mathrm{c}}$ & $\mathrm{r}_{\text {change }}=-0.01$ \\
\hline \multirow[t]{3}{*}{ Weight (kg) } & & 1 & $r_{13}=0.56^{c}$ & $\mathrm{r}_{13}=-0.14^{\mathrm{a}}$ & $r_{13}=-0.07$ & $r_{13}=0.06$ & $r_{13}=-0.37^{c}$ & $r_{13}=-0.04$ \\
\hline & & & $r_{17}=0.35^{c}$ & $r_{17}=-0.07$ & $r_{17}=0.07$ & $\mathrm{r}_{17}=0.09$ & $r_{17}=-0.19^{b}$ & $r_{17}=-0.11^{a}$ \\
\hline & & & $r_{\text {change }}=0.44^{c}$ & $\mathrm{r}_{\text {change }}=-0.08$ & $\mathrm{r}_{\text {change }}=-0.07$ & $r_{\text {change }}=-0.08$ & $\mathrm{r}_{\text {change }}=-0.25^{\mathrm{c}}$ & $r_{\text {change }}=-0.14^{\mathrm{a}}$ \\
\hline \multirow[t]{3}{*}{$\mathrm{BMD}\left(\mathrm{g} / \mathrm{cm}^{2}\right)$} & & & 1 & $r_{13}=-0.03$ & $r_{13}=-0.03$ & $\mathrm{r}_{13}=0.01$ & $r_{13}=-0.52^{c}$ & $r_{13}=-0.01$ \\
\hline & & & & $r_{17}=-0.09$ & $r_{17}=-0.01$ & $\mathrm{r}_{17}=0.08$ & $\mathrm{r}_{17}=-0.12^{\mathrm{a}}$ & $r_{17}=-0.02$ \\
\hline & & & & $\mathrm{r}_{\text {change }}=-0.01$ & $\mathrm{r}_{\text {change }}=-0.11$ & $\mathrm{r}_{\text {change }}=-0.06$ & $r_{\text {change }}=-0.26^{c}$ & $r_{\text {change }}=-0.07$ \\
\hline \multirow[t]{3}{*}{ RANKL (pmol/L) } & & & & 1 & $r_{13}=0.05$ & $r_{13}=-0.72^{c}$ & $\mathrm{r}_{13}=0.15^{\mathrm{a}}$ & $r_{13}=-0.03$ \\
\hline & & & & & $r_{17}=0.08$ & $r_{17}=-0.92^{c}$ & $r_{17}=0.23^{c}$ & $r_{17}=0.05$ \\
\hline & & & & & $r_{\text {change }}=0.03$ & $\mathrm{r}_{\text {change }}=-0.08$ & $\mathrm{r}_{\text {change }}=0.03$ & $\mathrm{r}_{\text {change }}=0.03$ \\
\hline \multirow[t]{3}{*}{ OPG (pmol/L) } & & & & & 1 & $r_{13}=0.60^{c}$ & $r_{13}=0.05$ & $r_{13}=-0.11$ \\
\hline & & & & & & $r_{17}=0.28^{c}$ & $r_{17}=-0.02$ & $r_{17}=-0.13^{a}$ \\
\hline & & & & & & $r_{\text {change }}=0.23^{c}$ & $\mathrm{r}_{\text {change }}=0.01$ & $\mathrm{r}_{\text {change }}=0.01$ \\
\hline \multirow[t]{3}{*}{ OPG/RANKL } & & & & & & 1 & $\mathrm{r}_{13}=-0.07$ & $r_{13}=-0.08$ \\
\hline & & & & & & & $r_{17}=-0.24^{c}$ & $r_{17}=-0.09$ \\
\hline & & & & & & & $\mathrm{r}_{\text {change }}=-0.03$ & $\mathrm{r}_{\text {change }}=-0.11^{\mathrm{a}}$ \\
\hline \multirow[t]{3}{*}{ CTX (ng/mL) } & & & & & & & 1 & $\mathrm{r}_{13}=-0.05$ \\
\hline & & & & & & & & $r_{17}=-0.01$ \\
\hline & & & & & & & & $\mathrm{r}_{\text {change }}=-0.01$ \\
\hline PINP (ng/mL) & & & & & & & & 1 \\
\hline
\end{tabular}

a $\mathrm{p}<0.05$.

b $\mathrm{p}<0.01$.

c $\mathrm{p}<0.001$. 

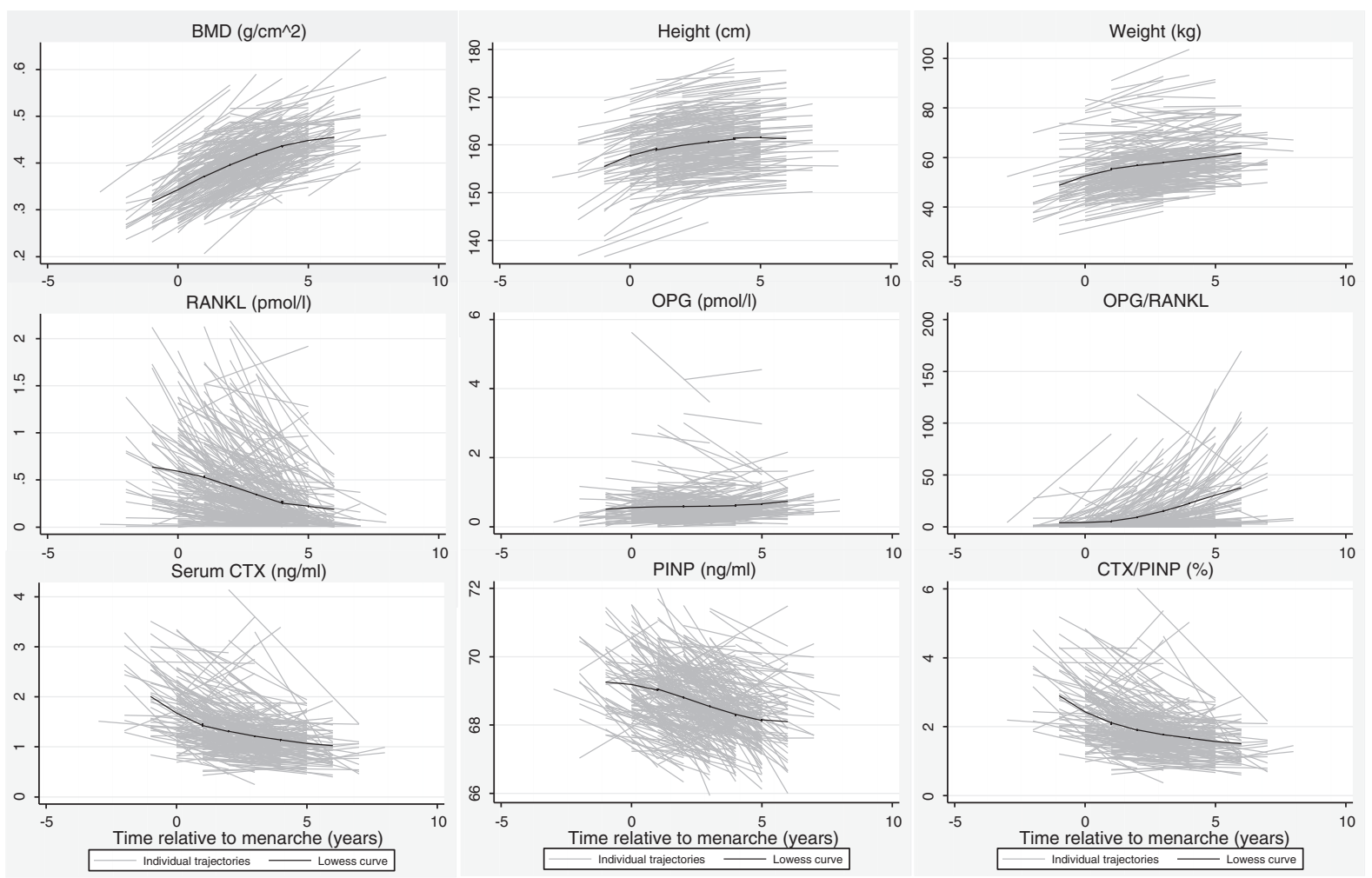

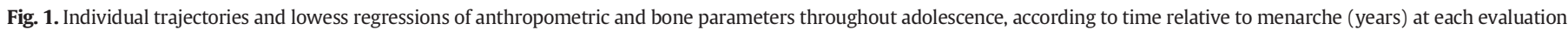

\section{Discussion}

In this population-based cohort of girls, serum RANKL and OPG levels varied markedly between early and late adolescence, independently of menarche timing. RANKL and OPG/RANKL were not correlated with turnover markers at 13 years of age, but became associated with bone resorption (CTX) in late adolescence.

Despite the major role of the RANK/RANKL/OPG system in the local regulation of bone turnover, there is a lack of prospective evidence on how serum levels of RANKL and OPG evolve throughout the life course. The absence of data on the relation between circulating levels of these cytokines and bone turnover is also recognized, and more so in females [14]. This may partly be explained by the yet uncertain significance of serum levels of these cytokines, mainly since they have important roles in other physiological and pathological functions, such as lactation, adaptive immunity, tumor proliferation, and regulation of body temperature [13]. Because of their unclear specificity towards bone metabolism, we cannot discard the hypothesis that the levels of OPG and/or RANKL in our study also reflected concomitant processes other than local communication within bone tissue.

Overall, we observed a decrease in serum RANKL between early and late adolescence, accompanied by an increase in serum OPG and a decrease in turnover markers of bone formation (PINP) and resorption (CTX). These changes occurred concomitantly with linear growth and with bone mineral accrual at the forearm, and are consistent with bone remodeling taking over, in relation to modeling, as the predominant process governing bone turnover in late adolescence [5]. Our results also suggest increasing variance in serum OPG to RANKL ratio with sexual development, even though the rate of change in each of those cytokines individually remained constant throughout time.

In our study, serum RANKL decreased with increasing age, as previously described in adults $[15,27,28]$. This finding, along with the direct correlation of RANKL with CTX in late adolescence, brings prospective evidence that serum RANKL is inversely related to skeletal maturity. Our study extends previous knowledge by showing that a substantial decrease in this cytokine is observable between 13 and 17 years of age in healthy girls. The rate of change in serum RANKL throughout adolescence was independent of sexual development, but the variance of RANKL bioactivity in the population, measured through the OPG/ RANKL ratio, was related to gynecologic maturity. In addition to being a key regulator in osteoclast biology, growing evidence shows that RANKL is a critical mediator of progesterone function in mammary gland development in animal models [29]. Therefore, besides reflecting increasing skeletal maturity, our observation that the rate of change in systemic RANKL bioactivity varied throughout sexual development is also compatible with a major role in the development of a functional mammary gland, although finer mechanistic explanations are beyond the scope of our present data.

We observed a slight but significant increase in serum OPG throughout adolescence, even though previous human studies do not clearly support this finding. One of the few studies conducted in children showed decreasing OPG levels up to 4 years of age, but constant levels from this age onwards up to adulthood [23]. Another cross-sectional study in adolescents found a gradual decrease in serum OPG with age but suggested that OPG levels in the postpubertal period were similar to those in young adults [30]. However, cross-sectional studies are clearly less robust for the estimation of average trajectories than our prospective design, since they underestimate underlying longitudinal changes [31]. Our finding of a weak association between serum levels of OPG and RANKL may be explained by a physiological dissociation between the relative expression of these cytokines during growth, previously reported in epiphyseal plates [11].

Most likely as a consequence of decreasing linear growth and bone modeling rates, average CTX and CTX/PINP levels in our sample decreased from early to late adolescence, in the overall sample, and a plateau was found in girls of older gynecologic age. This decreasing intensity of bone resorption towards the end of adolescence, because of diminishing rate or extension of matrix degradation, is consistent with the attainment of skeletal maturity, and has been previously described using crosssectional evidence $[22,32,33]$. It is also compatible with our observation 
Table 3

Fixed and random effects linear regression parameters for the associations between anthropometric and bone parameters and time relative to menarche.

\begin{tabular}{|c|c|c|c|c|}
\hline & \multicolumn{3}{|c|}{ Fixed effects } & \multirow{2}{*}{$\frac{\text { Random effects }}{\text { Individual-level standard-deviation }}$} \\
\hline & Intercept & Time (years) & Squared time (years ${ }^{2}$ ) & \\
\hline \multicolumn{5}{|c|}{$\mathrm{BMD}\left(\mathrm{mg} / \mathrm{cm}^{2}\right)$} \\
\hline Model 0 & $402^{\mathrm{a}}$ & - & - & 25.2 \\
\hline Model 1 & $348^{\mathrm{a}}$ & $21.8^{\mathrm{a}}$ & - & 39.2 \\
\hline Model 2 & $343^{\mathrm{a}}$ & $31.4^{\mathrm{a}}$ & $-1.8^{\mathrm{a}}$ & 40.8 \\
\hline \multicolumn{5}{|l|}{ Height (cm) } \\
\hline Model 0 & $160.0^{\mathrm{a}}$ & - & - & 5.4 \\
\hline Model 1 & $157.7^{\mathrm{a}}$ & $0.86^{\mathrm{a}}$ & - & 5.6 \\
\hline Model 2 & $157.4^{\mathrm{a}}$ & $1.62^{\mathrm{a}}$ & $-0.14^{\mathrm{a}}$ & 5.6 \\
\hline \multicolumn{5}{|l|}{ Weight (kg) } \\
\hline Model 0 & $57.2^{\mathrm{a}}$ & - & - & 9.8 \\
\hline Model 1 & $53.7^{\mathrm{a}}$ & $1.35^{\mathrm{a}}$ & - & 9.8 \\
\hline Model 2 & $53.3^{\mathrm{a}}$ & $2.44^{\mathrm{a}}$ & $-0.21^{\mathrm{a}}$ & 9.8 \\
\hline \multicolumn{5}{|c|}{ RANKL (pmol/L) } \\
\hline Model 0 & $0.39^{\mathrm{a}}$ & - & - & 0.17 \\
\hline Model 1 & $0.62^{\mathrm{a}}$ & $-0.09^{a}$ & - & 0.26 \\
\hline \multicolumn{5}{|c|}{$\mathrm{OPG}(\mathrm{pmol} / \mathrm{L})$} \\
\hline Model 0 & $0.60^{\mathrm{a}}$ & - & - & 0.45 \\
\hline Model 1 & $0.54^{\mathrm{a}}$ & $0.02^{\mathrm{a}}$ & - & 0.45 \\
\hline \multicolumn{5}{|c|}{ Log (OPG/RANKL) } \\
\hline Model 0 & $0.97^{\mathrm{a}}$ & - & - & 0.32 \\
\hline Model 1 & -0.25 & $0.48^{\mathrm{a}}$ & - & 1.07 \\
\hline \multicolumn{5}{|c|}{ CTX (ng/mL) } \\
\hline Model 0 & $1.31^{\mathrm{a}}$ & - & - & 0.34 \\
\hline Model 1 & $1.60^{\mathrm{a}}$ & $-0.11^{\mathrm{a}}$ & - & 0.33 \\
\hline Model 2 & $1.63^{\mathrm{a}}$ & $-0.19^{\mathrm{a}}$ & $0.01^{\mathrm{a}}$ & 0.33 \\
\hline \multicolumn{5}{|c|}{ PINP (ng/mL) } \\
\hline Model 0 & $68.7^{\mathrm{a}}$ & - & - & 0.40 \\
\hline Model 1 & $69.2^{\mathrm{a}}$ & $-0.22^{\mathrm{a}}$ & - & 0.59 \\
\hline \multicolumn{5}{|c|}{ CTX/PINP (\%) } \\
\hline Model 0 & $1.91^{\mathrm{a}}$ & - & - & 0.51 \\
\hline Model 1 & $2.31^{\mathrm{a}}$ & $-0.16^{a}$ & - & 0.49 \\
\hline Model 2 & $2.35^{\mathrm{a}}$ & $-0.26^{\mathrm{a}}$ & $0.02^{\mathrm{a}}$ & 0.49 \\
\hline
\end{tabular}

${ }^{\mathrm{a}} \mathrm{p}<0.001$.

of an inverse correlation between BMD and CTX. We observed a small decrease in average PINP levels throughout adolescence, with no relation to menarche timing. This is in agreement with a previous study, in which a PINP peak in girls was found from 10 to 13 years of age (coinciding with peak height velocity) and then decreased at a lower rate up to early adulthood [34].

In addition to the expected average increase in height and forearm BMD between 13 and 17 years of age in the whole sample, we observed a lower yearly rate of change in height as well as in bone density in girls with more advanced sexual development. Early maturing adolescents have younger average age at peak height and bone accrual velocities and, in the present sample, the fastest changes in bone size and mineralization probably occurred before 13 years of age [18,35]. Additionally, it is well-known that linear growth peaks earlier than bone accrual velocity [36,37], which likely explains our stronger association of gynecologic age with BMD than with height. Overall, we observed weak correlations between forearm BMD and serum parameters, namely osteoclast-regulating cytokines and PINP, in early and late adolescence. This dissociation is compatible with BMD being the result of accumulated exposures throughout life, while serum parameters are comparatively obtained as instantaneous measurements.

As dynamic measures, serum parameters of bone turnover may be subject to substantial variation, independently of meaningful differences between individuals or measurements [9]. We minimized preanalytical variability by collecting samples between 8 and 10 am and after a 12-hour overnight fast, using the same protocol in both evaluations and standardizing specimen collection, processing and storage. Additionally, these sources of variability are more relevant at the individual level, when comparisons with reference values or prognosis monitoring are the aim. This study aimed at describing relative changes in bone parameters from early to late adolescence and to assess the correlations between them rather than establishing normative values. Since we have no reason to believe that the ranks of individuals in the distributions were differentially affected, we do not think that intra-assay variability has substantially biased our conclusions. Another important aspect is that we assumed that individual variations in serum parameters could be validly described using linear trajectories. Although other trajectories are possible, previous studies have described nearly linear age-related decreases in bone turnover markers in the 13-17 year range [22,32,34]. Finally, due to the evaluation setting, we used peripheral dual-energy $\mathrm{X}$-ray absorptiometry to estimate bone density. The main implication is that intraindividual differences in forearm areal BMD are partly due to linear growth rather than to changes in intrinsic bone strength. However, this is not a disadvantage since bone size is also an important determinant of overall resistance to fracture [38].

Prospective cohort studies are subject to differential losses to followup as supported by the comparison we present in the Materials and methods section. Also, closed cohorts by design cannot account for underlying changes in the source population. Ultimately the extent to which the cohort represents the source population throughout follow-up is likely to decrease over time but we believe that this does not preclude the generation of epidemiological evidence in this particular case since our main objective was not to describe normative values, which would require representativeness. Our goal in this study was to estimate associations between markers of bone development and average trajectories in a community-based cohort of teenagers, thereby improving knowledge beyond the clinical scope. We believe that this is conveyed by the generally healthy profile of the sample presented in the Results section. In this case we have no material reason to believe that the associations estimated may differ among girls whose information we could not collect.

A major advantage of our study with relation to previously published research is that we used prospective data collected from girls born in the same year, thereby avoiding several sources of confounding. Another important strength of the study is that we were able to provide a 
multidimensional description of bone dynamics throughout adolescence by comprising parameters that represent different features of bone status and metabolism. This is particularly interesting regarding OPG and RANKL, since populational data were scarce.

In this cohort of healthy girls, serum RANKL and OPG levels varied markedly with sexual development in adolescence. These cytokines were not predictive of bone turnover or bone mineral density at 13 years of age, but serum RANKL bioactivity was associated with bone resorption in late adolescence.

\section{Declaration of interest}

The authors declare that there is no conflict of interest that could be perceived as prejudicing the impartiality of the research reported here.

\section{Funding}

The present work was funded by the Fundação para a Ciência e a Tecnololgia, grants PTDC/SAU-ESA/108407/2008, PTDC/SAU-EPI/ 115254/2009, EXPL/DTP-EPI/0280/2012.

\section{Acknowledgments}

The authors gratefully acknowledge Associação Portuguesa de Osteoporose (APO) for making the bone densitometry equipment available for both evaluations.

\section{References}

[1] Heaney RP, Abrams S, Dawson-Hughes B, Looker A, Marcus R, Matkovic V, et al. Peak bone mass. Osteoporos Int 2000;11:985-1009.

[2] Bouxsein ML. Determinants of skeletal fragility. Best Pract Res Clin Rheumatol 2005;19:897-911.

[3] Cooper C, Cole ZA, Holroyd CR, Earl SC, Harvey NC, Dennison EM, et al. Secular trends in the incidence of hip and other osteoporotic fractures. Osteoporos Int 2011;22:1277-88.

[4] Robling AG, Castillo AB, Turner $\mathrm{CH}$. Biomechanical and molecular regulation of bone remodeling. Annu Rev Biomed Eng 2006;8:455-98.

[5] Seeman E. Structural basis of growth-related gain and age-related loss of bone strength. Rheumatology (Oxford) 2008;47(Suppl. 4):iv2-8.

[6] Karsenty G, Ferron M. The contribution of bone to whole-organism physiology. Nature 2012;481:314-20.

[7] Kawai M, Devlin MJ, Rosen CJ. Fat targets for skeletal health. Nat Rev Rheumatol 2009;5:365-72.

[8] Leibbrandt A, Penninger JM. RANK/RANKL: regulators of immune responses and bone physiology. Ann N Y Acad Sci 2008:1143:123-50.

[9] Vega D, Maalouf NM, Sakhaee K. Clinical review \#: the role of receptor activator of nuclear factor-kappaB (RANK)/RANK ligand/osteoprotegerin: clinical implications. J Clin Endocrinol Metab 2007;92:4514-21.

[10] Fuller K, Kirstein B, Chambers TJ. Regulation and enzymatic basis of bone resorption by human osteoclasts. Clin Sci (Lond) 2007;112:567-75.

[11] Boyce BF, Xing L. Functions of RANKL/RANK/OPG in bone modeling and remodeling. Arch Biochem Biophys 2008:473:139-46.

[12] Hanada R, Hanada T, Penninger JM. Physiology and pathophysiology of the RANKL/ RANK system. Biol Chem 2010;391:1365-70.

[13] Boyce BF, Xing L. Biology of RANK, RANKL, and osteoprotegerin. Arthritis Res Ther 2007;9(Suppl. 1):S1.

[14] Findlay DM, Atkins GJ. Relationship between serum RANKL and RANKL in bone. Osteoporos Int 2011;22:2597-602.

[15] Wagner D, Fahrleitner-Pammer A. Levels of osteoprotegerin (OPG) and receptor activator for nuclear factor kappa b ligand (RANKL) in serum: are they of any help? Wien Med Wochenschr 2010;160:452-7.
[16] Leeming DJ, Alexandersen P, Karsdal MA, Ovist P, Schaller S, Tanko LB. An update on biomarkers of bone turnover and their utility in biomedical research and clinical practice. Eur J Clin Pharmacol 2006;62:781-92.

[17] Vasikaran S, Eastell R, Bruyere O, Foldes AJ, Garnero P, Griesmacher A, et al. Markers of bone turnover for the prediction of fracture risk and monitoring of osteoporosis treatment: a need for international reference standards. Osteoporos Int 2011;22:391-420.

[18] McKay HA, Bailey DA, Mirwald RL, Davison KS, Faulkner RA. Peak bone mineral accrual and age at menarche in adolescent girls: a 6-year longitudinal study. J Pediatr 1998;133:682-7.

[19] Dimitri P, Wales JK, Bishop N. Adipokines, bone-derived factors and bone turnover in obese children; evidence for altered fat-bone signalling resulting in reduced bone mass. Bone 2011:48:189-96.

[20] van der Sluis IM, Hop WC, van Leeuwen JP, Pols HA, de Muinck Keizer-Schrama SM. A cross-sectional study on biochemical parameters of bone turnover and vitamin D metabolites in healthy Dutch children and young adults. Horm Res 2002;57:170-9.

[21] Cadogan J, Blumsohn A, Barker ME, Eastell R. A longitudinal study of bone gain in pubertal girls: anthropometric and biochemical correlates. J Bone Miner Res 1998;13:1602-12.

[22] Walsh JS, Henry YM, Fatayerji D, Eastell R. Hormonal determinants of bone turnover before and after attainment of peak bone mass. Clin Endocrinol (Oxf) 2010;72:320-7.

[23] Buzi F, Maccarinelli G, Guaragni B, Ruggeri F, Radetti G, Meini A, et al. Serum osteoprotegerin and receptor activator of nuclear factors $\mathrm{kB}$ (RANKL) concentrations in normal children and in children with pubertal precocity, Turner's syndrome and rheumatoid arthritis. Clin Endocrinol (Oxf) 2004;60:87-91.

[24] Munoz-Calvo MT, Barrios V, de Alvaro MT Garcia, Lefort M, Mendez-Davila C, Argente J, et al. Maintained malnutrition produces a progressive decrease in (OPG)/RANKL ratio and leptin levels in patients with anorexia nervosa. Scand J Clin Lab Invest 2007;67:387-93.

[25] Osorio A, Ortega E, Torres JM, Sanchez P, Ruiz-Requena E. Mineral-bone metabolism markers in young hemodialysis patients. Clin Biochem 2011;44:1425-8.

[26] Ramos E, Barros H. Family and school determinants of overweight in 13-year-old Portuguese adolescents. Acta Paediatr 2007;96:281-6.

[27] Abrahamsen B, Hjelmborg JV, Kostenuik P, Stilgren LS, Kyvik K, Adamu S, et al. Circulating amounts of osteoprotegerin and RANK ligand: genetic influence and relationship with BMD assessed in female twins. Bone 2005;36:727-35.

[28] Kerschan-Schindl K, Wendlova J, Kudlacek S, Gleiss A, Woloszczuk W, Pietschmann P. Serum levels of receptor activator of nuclear factor kappaB ligand (RANKL) in healthy women and men. Exp Clin Endocrinol Diabetes 2008:116:491-5.

[29] Tanos T, Sflomos G, Echeverria PC, Ayyanan A, Gutierrez M, Delaloye JF, et al. Progesterone/RANKL is a major regulatory axis in the human breast. Sci Transl Med 2013;5:182ra55.

[30] Gajewska J, Ambroszkiewicz J, Laskowska-Klita T. Osteoprotegerin and C-telopeptide of type I collagen in polish healthy children and adolescents. Adv Med Sci 2006; 51:269-72.

[31] Cole T], Cortina-Borja M, Sandhu J, Kelly FP, Pan H. Nonlinear growth generates age changes in the moments of the frequency distribution: the example of height in puberty. Biostatistics 2008;9:159-71.

[32] Alberti C, Chevenne D, Mercat I, Josserand E, Armoogum-Boizeau P, Tichet J, et al. Serum concentrations of insulin-like growth factor (IGF)-1 and IGF binding protein-3 (IGFBP-3), IGF-1/IGFBP-3 ratio, and markers of bone turnover: reference values for french children and adolescents and z-score comparability with other references. Clin Chem 2011;57:1424-35.

[33] Rauchenzauner M, Schmid A, Heinz-Erian P, Kapelari K, Falkensammer G Griesmacher A, et al. Sex- and age-specific reference curves for serum markers of bone turnover in healthy children from 2 months to 18 years. J Clin Endocrinol Metab 2007:92:443-9.

[34] Crofton PM, Evans N, Taylor MR, Holland CV. Procollagen type I amino-terminal propeptide: pediatric reference data and relationship with procollagen type I carboxyl-terminal propeptide. Clin Chem 2004;50:2173-6.

[35] Iuliano-Burns S, Mirwald RL, Bailey DA. Timing and magnitude of peak height velocity and peak tissue velocities for early, average, and late maturing boys and girls. Am J Hum Biol 2001;13:1-8.

[36] Veldhuis JD, Roemmich JN, Richmond EJ, Rogol AD, Lovejoy JC, Sheffield-Moore M, et al. Endocrine control of body composition in infancy, childhood, and puberty. Endocr Rev 2005;26:114-46.

[37] Jackowski SA, Erlandson MC, Mirwald RL, Faulkner RA, Bailey DA, Kontulainen SA, et al. Effect of maturational timing on bone mineral content accrual from childhood to adulthood: evidence from 15 years of longitudinal data. Bone 2011;48:1178-85.

[38] Bachrach LK. Dual energy X-ray absorptiometry (DEXA) measurements of bone density and body composition: promise and pitfalls. J Pediatr Endocrinol Metab 2000;13(Suppl. 2):983-8. 